\title{
Thanks to Jim Bieman, the Former Editor-in-Chief of the Software Quality Journal
}

\author{
Rachel Harrison
}

Published online: 18 February 2009

(C) Springer Science+Business Media, LLC 2009

My first job as Editor-in-Chief of the Software Quality Journal must be to thank Jim Bieman for his excellent stewardship at the helm of the journal. For the past 7 years Jim has successfully worked to raise awareness of the journal, continually producing high quality issues containing research papers with cutting-edge results, as well as pragmatic papers that provide practical advice for those wishing to build high quality systems. Jim will remain on the Software Quality Journal Editorial Board, so that we can continue to benefit from his years of experience and expertise.

As Editor-in-Chief my aim is to increase the throughput of papers whilst maintaining and improving the quality of each issue. I believe that this journal must continue to publish papers that are of interest both to the academic community and to those working in the real world. Thus I intend to build on the firm foundations that Jim has constructed so well and carry on in the manner that he established. In addition I would very much like to see more papers with empirical results in order to encourage an objective and scientific evaluation of the research performed by our community. If you have any ideas about how we can take the Software Quality Journal forward, please do not hesitate to contact me.

R. Harrison $(\bowtie)$

Computer Science Department, The University of Reading, Reading RG6 6AY, UK

e-mail: rachel.harrison@ reading.ac.uk 